
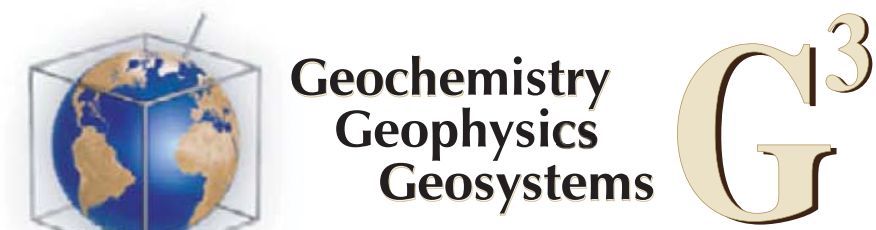

\title{
Velocity structure beneath the southern Puna plateau : Evidence for delamination
}

\author{
Frank J. Calixto and Eric Sandvol \\ Department of Geological Sciences, University of Missouri-Columbia, Columbia, Missouri, USA \\ (fjc5h3@mail.missouri.edu)
}

Suzanne Kay and Patrick Mulcahy

Department of Earth and Atmospheric Sciences, Cornell University, Ithaca, New York, USA

\section{Benjamin Heit and Xiaohui Yuan}

Deutsches GeoForschungsZentrum GFZ, Telegrafenberg, Potsdam, Germany

\section{Beatriz Coira}

CONICET, Instituto de Geología y Minería, Universidad Nacional de Jujuy, San Salvador de Jujuy, Argentina

\author{
Diana Comte \\ Departamento de Geofisica, Universidad de Chile, Santiago, Chile
}

\section{Patricia Alvarado \\ Departamento de Geofisica, Universidad Nacional de San Juan, San Juan, Argentina}

[1] The high elevation of the southern Puna plateau, the widespread melting of its crust, the gap in intermediate depth seismicity and the recent eruptions of ignimbrite complexes can be explained by delamination of the lithospheric mantle beneath it. To test this hypothesis, an array consisting of 73 broad band and short period seismic stations was deployed in the region for a period of 2 years starting in 2007. We inverted the data using the two plane wave approach and obtained 1-D and 3-D Rayleigh wave phase velocities. Our dispersion curve shows that at short periods $(<70 \mathrm{~s})$ the phase velocities are slightly higher than those of the Tibetan plateau and lower than those of the Anatolian plateau. At periods of 100-140 s we observe a low velocity zone that might be remnant hot asthenosphere below a flat slab (7-10 Ma). We estimate the average continental lithosphere thickness for the region to be between 100 and $130 \mathrm{~km}$. Our three-dimensional Rayleigh wave phase velocities show a high velocity anomaly at low frequencies $(0.007$, 0.008 , and $0.009 \mathrm{~Hz}$ ) slightly to the north of Cerro Galan. This would be consistent with the hypothesis of delamination in which a piece of lithosphere has detached and caused upwelling of hot asthenosphere, which in turn caused widespread alkaline-collision related volcanism. This interpretation is also corroborated by our shear wave velocity model, where a high velocity anomaly beneath the northern edge of Cerro Galan at $130 \mathrm{~km}$ depth is interpreted as the delaminated block on top of the subducting Nazca slab.

Components: 7,738 words, 8 figures.

Keywords: southern Puna Plateau; delamination; surface wave tomography.

Index Terms: 7240 Subduction zones: Seismology; 7255 Surface waves and free oscillations: Seismology; 7260 Theory: Seismology; 1207 Transient deformation: Geodesy and Gravity; 1219 Gravity anomalies and Earth structure: Geodesy and Gravity; 1240 Satellite geodesy: results: Geodesy and Gravity; 8104 Continental margins: convergent: Tectonophysics; 8178 Tectonics and magmatism: Tectonophysics.

Received 1 May 2013; Revised 30 August 2013; Accepted 31 August 2013; Published 2 October 2013. 
Calixto, F. J., E. Sandvol, S. Kay, P. Mulcahy, B. Heit, X. Yuan, B. Coira, D. Comte, and P. Alvarado (2013), Velocity structure beneath the southern Puna plateau: Evidence for delamination, Geochem. Geophys. Geosyst., 14, 4292-4305, doi:10.1002/ggge.20266.

\section{Introduction}

[2] The southern Puna plateau $\left(25^{\circ} \mathrm{S}-28^{\circ} \mathrm{S}\right)$ offers an excellent natural laboratory to study the formation and evolution of a continental plateau along an active continental margin. The Puna-Altiplano plateau has numerous important features that set it apart from much of the rest of the Andean mountain belt. Such features include a distinctive spatial and geochemical pattern of mafic lavas and giant ignimbrites, a high topography with a large deficit of crustal shortening, and a slab with a gap in intermediate depth seismicity. The slab has a steeper segment to the north and a flat segment to the south. This region is also believed to have hosted a series of delamination events starting 6-7 Ma with the most recent occurring around $2 \mathrm{Ma}$ [Kay and Kay, 1993; Kay and Coira, 2009]. We believe that we have imaged the delaminated block as a region of abnormally high shear wave velocities on top of the subducting slab at a depth of around $150 \mathrm{~km}$ slightly to the north of the Cerro Galan ignimbrite.

[3] The Andean Mountain Range (Figure 1) is the typical example of an active continental margin and the associated mountain building processes. The Andes are characterized by the high, active volcanoes $(>6000 \mathrm{~m}$, with Ojos del Salado being the highest at $6890 \mathrm{~m}$ ), high peaks (Aconcagua is the highest peak with $6959 \mathrm{~m}$ ), and some of thickest crust on earth $(>70 \mathrm{~km})$, the second greatest plateau with the largest Tertiary ignimbrite calderas, and among the most shortened continental crust. By comparison the crustal thickness of the Tibetan plateau ranges from 63 to $72 \mathrm{~km}$ [Holt and Wallace, 1990], the northern Tibet has a crustal thickness of $55-75 \mathrm{~km}$ [Herquel et al., 1995] with felsic composition, probably generated from partially melted sedimentary rocks [Wang et al., 2012]; and the crustal thickness of Eastern Turkey ranges from 40 to $50 \mathrm{~km}$ [Zor et al., 2003] with intermediate composition composed mainly of andesite and dacite [Karsli et al., 2010]. The Andes are a perfect place for investigating the effects of shallowly subducting oceanic plates [Isacks, 1988; Cahill and Isacks, 1992], continental lithosphere removal by fore-arc subduction erosion [Von Huene and Scholl, 1991; Kay et al.,
2005], and delamination of continental and mantle lithosphere [Kay and Kay, 1993; Beck and Zandt, 2002; Sobolev and Babeyko, 2005].

[4] Kay and Kay [1993] proposed a model with an episode or perhaps episodes of crustal and lithospheric delamination to explain a number of geodynamic features of the Central Andean plateau and particularly in the southern Puna plateau, such as the distinctive spatial and geochemical pattern of the mafic lavas and giant ignimbrite fields, the high topography with a large deficit in crustal shortening, and a slab with a gap in intermediate depth seismicity. However, the mechanism and extent of delamination remains controversial. The first delamination models (proposed for the western US and Tibet, not the Andes) used delamination of mantle lithosphere to explain rapid uplift, extension and rapid variation of regional stress, lithospheric thinning and increased magmatism [Bird, 1979; England and Houseman, 1988]. Kay and Kay [1993] and Kay et al. [1994] used the delamination model to explain similar features in the southern Puna plateau of the central Andes. Nonetheless, their model has a fundamental difference from previous models, because they include the removal and sinking of dense eclogitic crust along with lithospheric mantle. This could lead to larger density contrast that accounts for the gravitational potential energy needed for delamination to occur [Kay and Kay, 1993]. However, the scale and mechanism of this type of delamination are still not well understood.

[5] The current models suggest that delamination occurs either as lithospheric pieces and drips falling in the asthenosphere [Jull and Keleman, 2002; Babeyko et al., 2002; Sobolev and Babeyko, 2005], or as large crustal and lithospheric blocks being removed, like those proposed for Sierra Nevada [e.g., Ducea et al., 2003]. An important reason to consider crustal delamination in the Andes is that it helps to explain the apparent paradox of mantle-derived magmas entering the crust that are basaltic in composition, yet the bulk composition of the crust is andesitic. One way to explain crustal composition is to preferentially remove dense mafic eclogitic roots of thickened continental crust [Kay and Kay, 1993; Rudnick, 1995]. Such a 


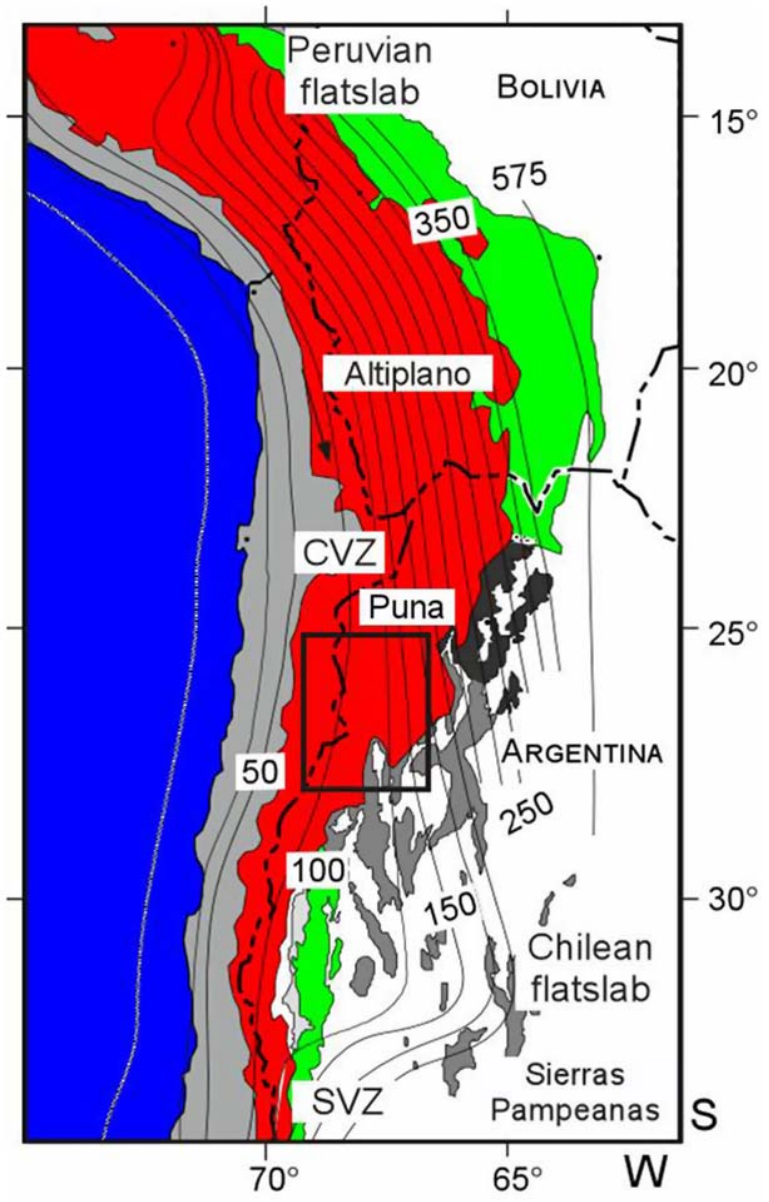

Figure 1. Andean Orogeny and region of study — southern Puna plateau, shown in the black rectangle. Slab contours show the southward transition from shallow subduction to normal subduction toward the north [Cahill and Isacks, 1992].

model would include crustal delamination which removes lower crust, sediment subduction which removes upper crust, forearc subduction erosion which removes both lower and upper crust, and slab break-off which primarily removes lower crust. However, only the removal of mafic crust helps to resolve the andesitic crustal paradox. In this context, the southern Puna plateau is an excellent place to test models for crustal delamination and ultimately crustal destruction and recycling. This study aims to provide geophysical evidence to prove or disprove the delamination hypothesis in the southern Puna plateau. If delamination indeed occurred, then it is important to explore whether it occurred as a single block or multiple delaminated bodies. We also want to examine the relationship between delamination, seismic gap, abnormal upwelling of the region and the eruption of the recent ignimbrite complexes.

\section{Data Processing}

[6] We use fundamental mode Rayleigh waves recorded at the Puna array within the boundaries: 24-29 $\mathrm{S}$ and $64-71^{\circ} \mathrm{W}$. About 50 teleseismic events with Ms > 5.9 and epicentral distances of $30^{\circ}-120^{\circ}$ from the center of the array were used. These events together with the 73 seismic stations (see Figure 2) generate a very dense ray coverage which allows us to resolve high-resolution phase velocity maps.

[7] We use only the vertical component and Rayleigh waves firstly removing all of the instrument responses, means and trends. Next, we filtered the seismograms in 13 narrow frequency bands ranging from 0.007 to $0.05 \mathrm{~Hz}$. Then we visually inspected the waveforms and discarded the ones with low signal-to-noise ratio. After that, we isolated the fundamental mode Rayleigh waves by windowing the filtered seismogram. The width of each cut is determined according to the width of the fundamental mode Rayleigh wave packet. Finally, the filtered and windowed seismograms are converted into the frequency domain in order to get amplitude and phase measurements. We normalized the amplitudes in order to prevent a bias resulting from variations in earthquake magnitude. We use high damping for Rayleigh wave velocities and anisotropy in order to minimize the trade off between lateral heterogeneity of Rayleigh wave velocities and anisotropy. We use a constant smoothing length of $65 \mathrm{~km}$ for all periods and a grid size of $0.25^{\circ}$ by $0.25^{\circ}$. Details of the data processing procedure are given in Yang and Forsyth [2006a, 2006b]. However, a brief summary of their method is presented in the next section.

\section{Surface Wave Tomography Method}

[8] Also known as the two plane wave approach, this method uses variations in amplitude and phase of the distorted wave front due to lateral velocity variations. This method also has the advantage of solving for distribution of anisotropy with frequency. This approach models the azimuthal variations of Rayleigh wave phase velocities $\left(\mathrm{V}_{\mathrm{ij}}\right)$ [Forsyth and $L i, 2005]$, which can be expressed as

$$
V_{i j}\left(w, \theta_{i j}\right)=\left(B_{0}\right)_{j}+\left(B_{1}\right)_{j} \cos \left(2 \theta_{i j}\right)+\left(B_{2}\right)_{j} \sin \left(2 \theta_{i j}\right)
$$

where $w$ is the frequency, $V_{\mathrm{ij}}$ is the phase velocity at the $j$ th grid point due to event $i, \theta_{\mathrm{ij}}$ is the backazimuth from the $j$ th grid point to the $i$ th event in 


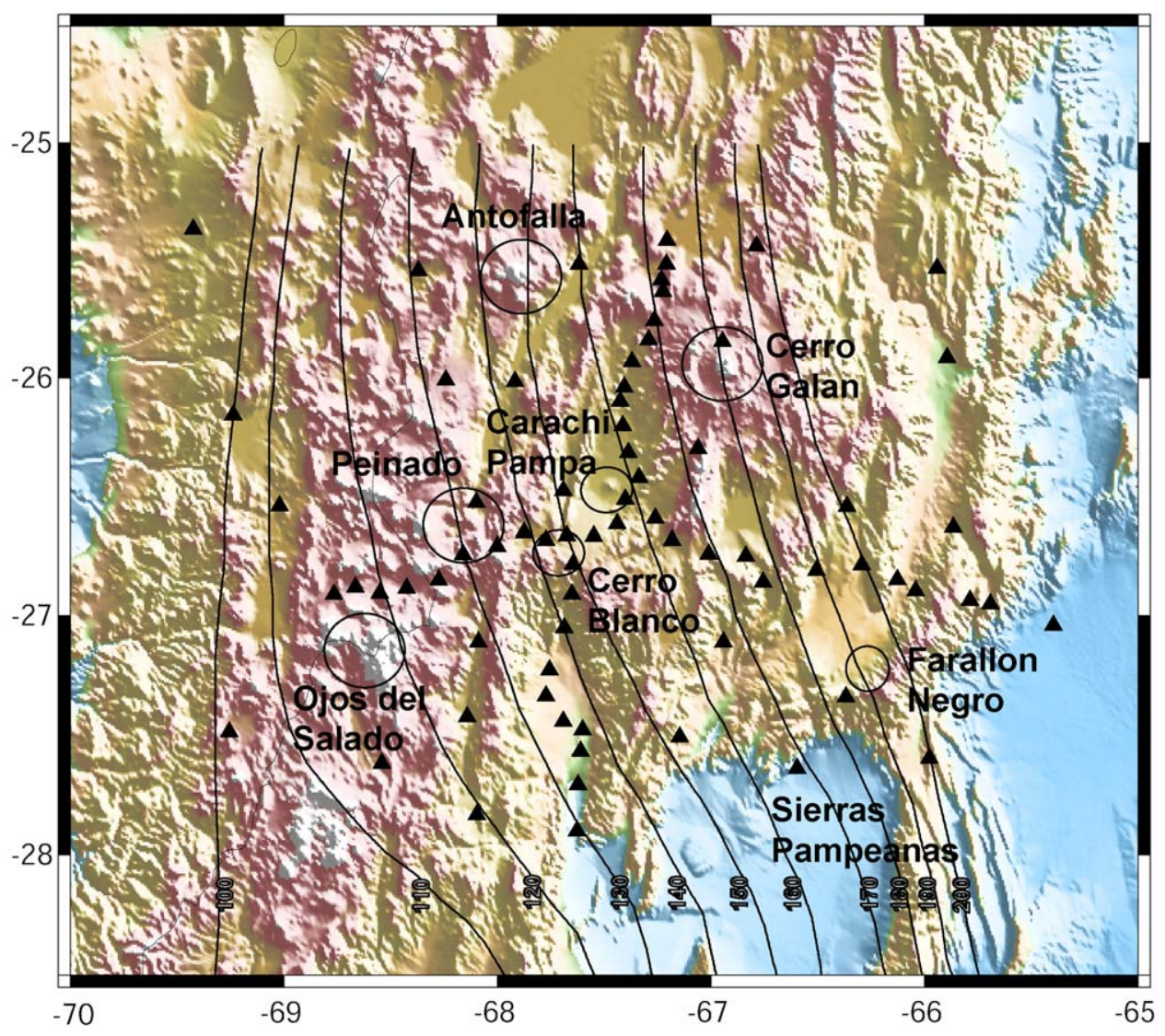

Figure 2. Station distribution (black triangles) along the southern Puna plateau. Antofalla, Cerro Galan, Ojos del Salado, Cerro Blanco, Carachi Pampa, Peinado, and Farallon Negro volcanic centers are shown, as well as the Sierras Pampeanas flat subduction region. The slab contours from 100 to $200 \mathrm{~km}$ depth are also shown [Mulcahy et al., 2010].

the geographic coordinate system, $B_{0}$ is the azimuthally averaged phase velocity, and $B_{1}$ and $B_{2}$ are azimuthal anisotropic coefficients. Thus, the phase velocity corresponding with an event $i$ at the grid point $j$ is described using three parameters. The above expression assumes that the higher order azimuthal terms can be neglected, which is an acceptable assumption for Rayleigh waves [Smith and Dahlen, 1973].

[9] The method also models the teleseismic wavefield using the sum of two plane waves at a given frequency $(w)$ for an event $i$. Each plane wave has initial unknown amplitude, phase and propagation direction. The vertical displacement $U_{z}$ is expressed as:

$$
\begin{aligned}
U_{z}(w)= & A_{1}(w) \exp \left[-i\left(\vec{k}_{1} \cdot \vec{x}-w t\right)\right] \\
& +A_{2}(w) \exp \left[-i\left(\vec{k}_{2} \cdot \vec{x}-w t\right)\right]
\end{aligned}
$$

where $A$ is the amplitude, $k$ is the horizontal wave number and $x$ is the position vector. In practice, these waves need to be expressed in the reference frame of the $j$ th grid point, where they can undergo either constructive or destructive interference, causing an interference pattern. Thus, at each frequency and grid point $j$, the incoming wavefield is described using six parameters: the amplitude, reference phase and direction of the two plane waves.

[10] The method also uses 2-D sensitivity kernels based on the first Born approximation, which takes into account finite frequency effects, together with the two plane wave method. This combination yields results with higher resolution at regional scales as compared to the results obtained by representing the sensitivity kernels with a Gaussian-shaped zone [Forsyth and $\mathrm{Li}$, $2005 ; L i, 2011]$. The use of finite frequency sensitivity kernels provides improved lateral resolution at deeper depths (generally below $50 \mathrm{~km}$ ) as compared to previous methods without sensitivity kernels. 

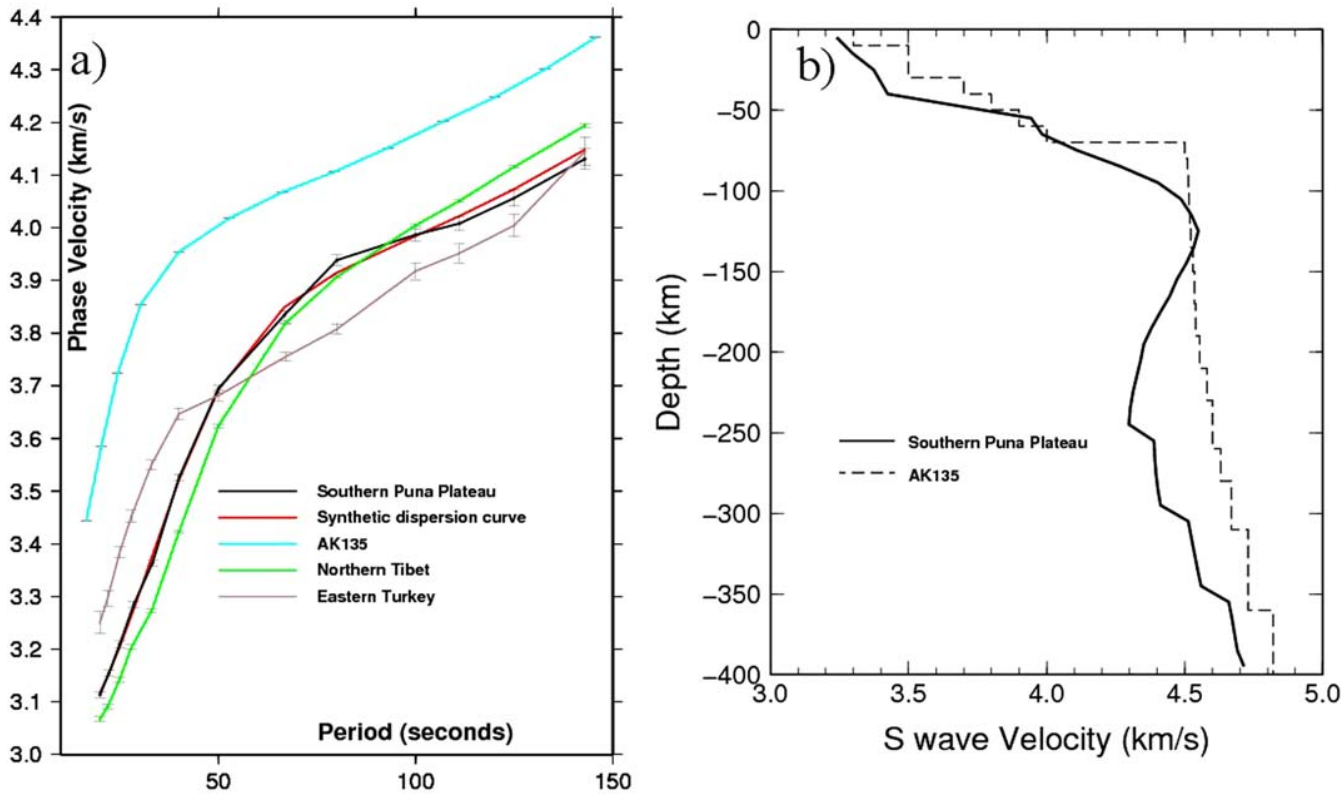

Figure 3. (a) Dispersion curve for the southern Puna plateau with standard deviation errors and a synthetic dispersion curve obtained from the 1-D shear wave model. The AK135, Northern Tibet [Ceylan et al., 2012] and Eastern Turkey dispersion curves are also shown for comparison. The southern Puna plateau exhibits a low velocity zone at periods greater than $100 \mathrm{~s}$. (b) (solid line) Inferred shear wave velocities showing the low velocity zone below $100 \mathrm{~km}$ and (dashed line) initial guess for 1-D shear wave velocity model (AK135).

\section{Dispersion Curve and Phase Velocities}

\subsection{Dispersion Curve and 1-D Shear Wave Velocity Model}

[11] Figure 3a shows that the crustal phase velocities in the southern Puna plateau (PP), below $40 \mathrm{~s}$, are about $5 \%$ slower than those of Eastern Turkey (ET) and 2\% faster than those of Northern Tibet (NT) [Ceylan et al., 2012]. Phase velocities at periods of $60-80 \mathrm{~s}$ are consistent with NT, but are 3\% faster than ET. At periods of $80-125 \mathrm{~s}$, the phase velocities are slower than NT by an average of $1.5 \%$ and faster than ET by $1 \%$. Figure $3 \mathrm{a}$ also shows a parallel shift of the AK135 curve with respect to the other three curves. The 1-D Rayleigh velocities were inverted to obtain average $S$ wave velocities for the region (Figure $3 b$ ). The average $S$ wave model suggests a continental lithosphere thickness between 100 and $130 \mathrm{~km}$. The $S$ wave model confirms the existence of a low velocity zone at depths below $130 \mathrm{~km}$. A synthetic dispersion curve was obtained from the Vs model and it fits the measured dispersion curve (Figure 3a).

\subsection{Resolution Test}

[12] We also performed a resolution test to estimate the extent to which the method and the station array are able to resolve velocity anomalies in our area. The same smoothing length and geometry used in the real inversion was applied here. We used a checkerboard with anomalies of size $1^{\circ} \times$ $1^{\circ}$ for short periods (20-80 s), and anomalies of size $1.5^{\circ} \times 1.5^{\circ}$ for longer periods $(80-143 \mathrm{~s})$. A series of synthetic amplitudes and phases were calculated and used to invert for the phase velocity structure. Figures 4 and 5 show the corresponding results. The resolution test shows that we should be able to resolve anomalies of $1^{\circ} \times 1^{\circ}$ or greater for short periods and $1.5^{\circ} \times 1.5^{\circ}$ or greater for long periods. Therefore, our inversions should be fairly reliable.

\subsection{Phase Velocities}

[13] Our surface wave phase velocity measurements (Figure 6) indicate the presence of a high phase velocity block beneath and slightly to the north of Cerro Galan, a very large ignimbrite volcanic center, at frequencies between 0.007 and $0.009 \mathrm{~Hz}$ (roughly between the peak sensitivity depths of 190 and $150 \mathrm{~km}$ ). Figure 6 only shows 


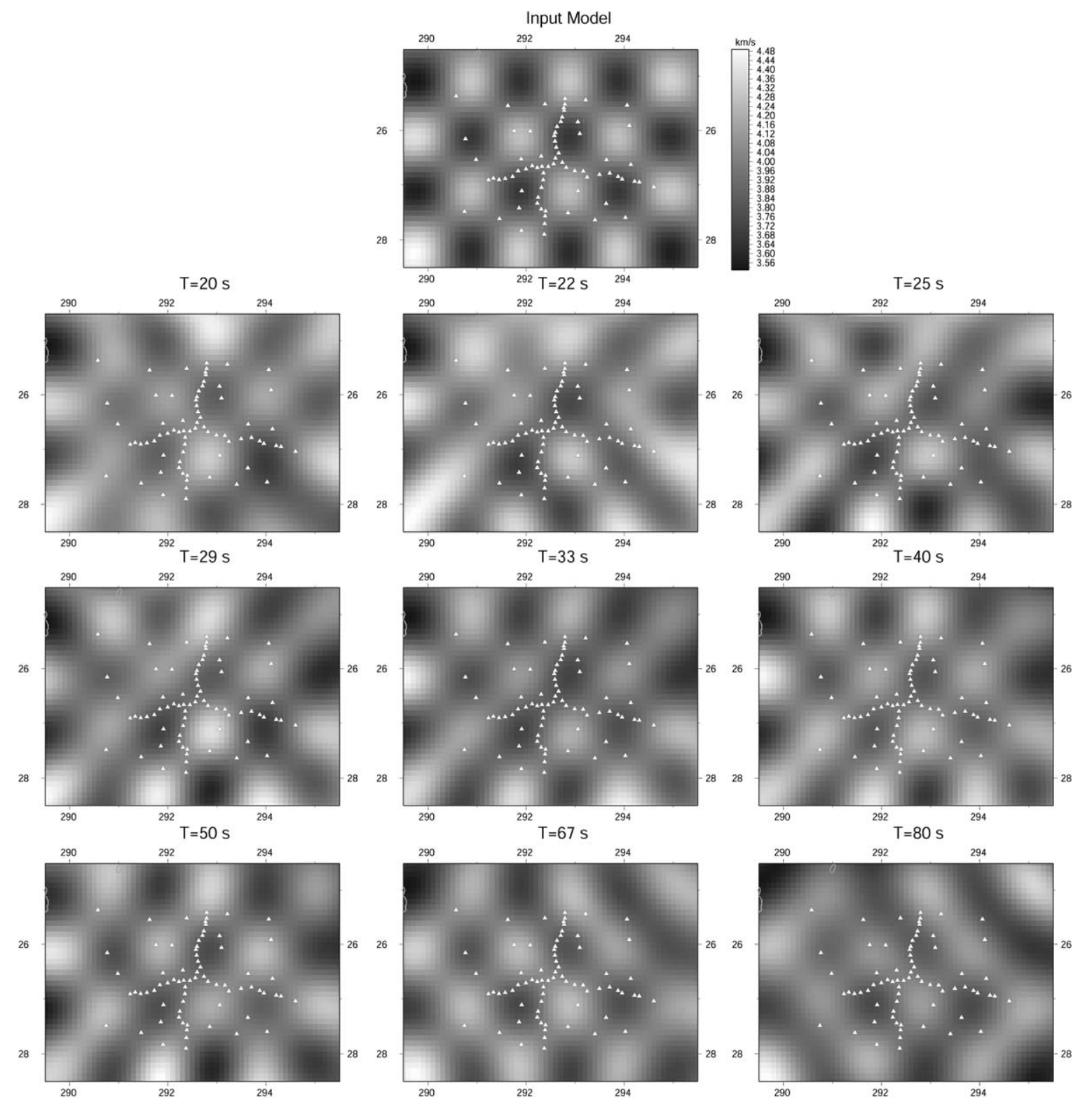

Figure 4. Resolution tests for a grid size $1^{\circ} \times 1^{\circ}$. The test yields acceptable results for periods of $20-80 \mathrm{~s}$.

phase velocities with standard deviation equal or less than $0.1 \mathrm{~km}$. The standard deviations are low near the center of the station array and increases toward the edges (not shown here but available as supporting information ${ }^{1}$ ). The standard deviations suggest that it is possible to obtain reliable results outside the station array $\left(71^{\circ} \mathrm{W}\right.$ to $65^{\circ} \mathrm{W}$ and $25^{\circ}$ $\mathrm{S}$ to $\left.29^{\circ} \mathrm{S}\right)$. At $0.0125 \mathrm{~Hz}(105 \mathrm{~km})$ we start to see the slab, which undergoes a transition from a normal angle of subduction in the north to a shallower regime in the south. At higher frequencies, 0.02

\footnotetext{
${ }^{1}$ Additional supporting information may be found in the online version of this article.
}

$\mathrm{Hz}(66 \mathrm{~km})$, a low velocity zone appears beneath and south-east of Cerro Galan, approaching Ojos del Salado. The low velocity zone gets wider for higher frequencies $(0.025-0.04 \mathrm{~Hz})$ or shallower depths, covering Peinado, Carachi Pampa, Cerro Blanco, Ojos del Salado, and part of Cerro Galan. The low velocity zone gets narrower again for $0.045 \mathrm{~Hz}$, covering only Peinado, Carachi Pampa, and western Cerro Galan. Figure 6 also shows an estimation of seismic anisotropy. The black lines are parallel to the fast direction and their size is proportional to the degree of seismic anisotropy. Overall, the mantle beneath this region seems to be weakly anisotropic for low frequencies (depths 


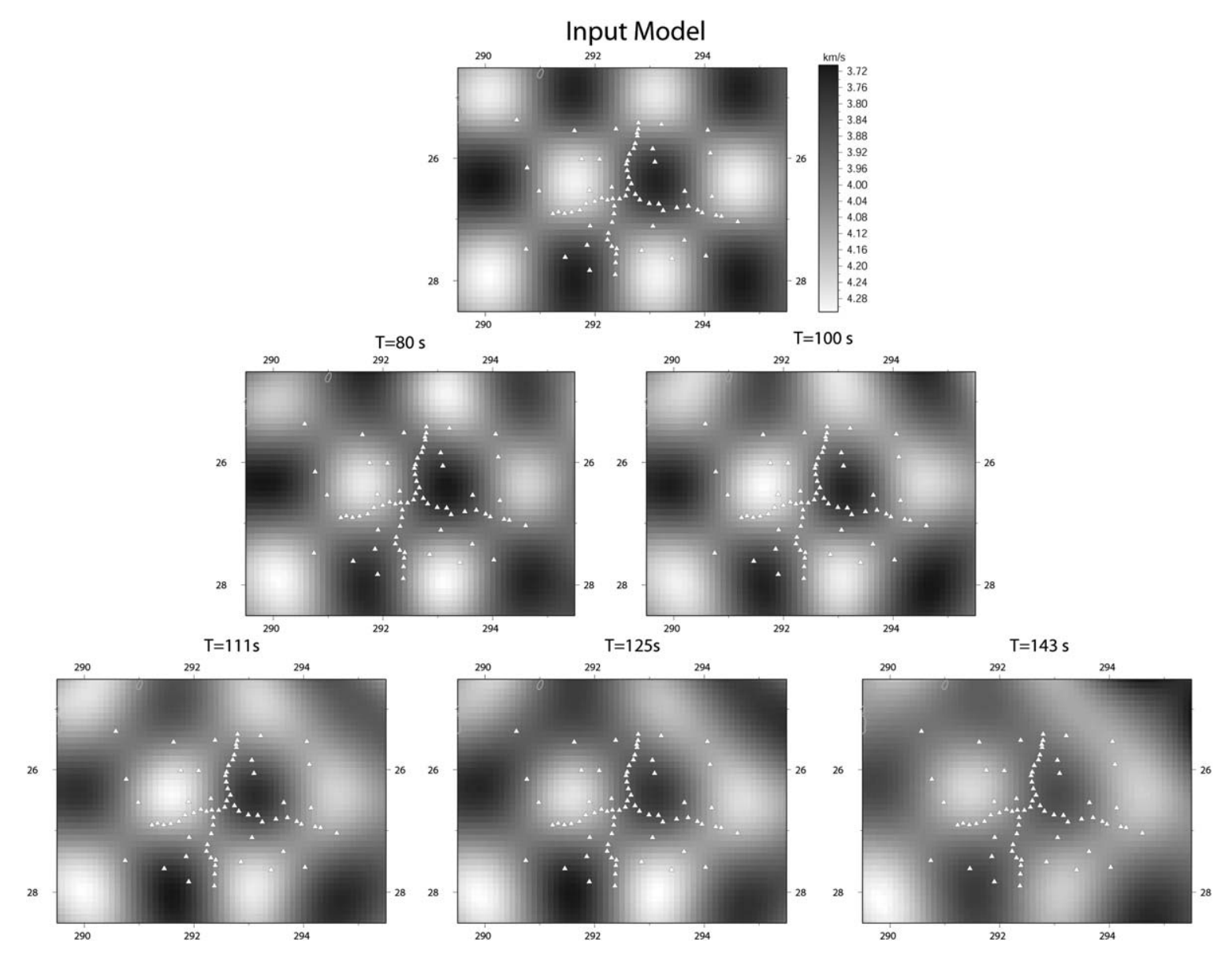

Figure 5. Resolution tests for a grid size $1.5^{\circ} \times 1.5^{\circ}$. This test yields acceptable results for all periods. However, here we only show the results for long periods.

of $190 \mathrm{~km}$ ), and anisotropy increases toward higher frequencies (shallower depths). Anisotropy also increases from west to east, which is expected in a west-east subduction setting. At crustal depths, the seismic anisotropy fast directions appear to have south-west north-east orientation.

\section{Shear Wave Velocity Structure}

[14] Although the phase velocity measurements give us an idea of the velocity structure, it only provides depth averages of phase velocities as a function of frequency. Here we used the method developed by Saito [1988] and inverted our Rayleigh wave phase velocity measurements to obtain shear wave velocities as a function of depth. For the 1-D inversion (Figure 3, right), the model AK135 is used as the starting model with a crustal thickness of $55 \mathrm{~km}$. For the 3-D inversion, we simply performed the 1-D inversion at each map point using the 1-D result (Figure 3, right) as the starting model. Figure 7 shows the results as various relative shear wave velocity east-west cross sections.
We also plot the seismicity obtained from the PDE catalog and the slab contours from Mulcahy et al. [2010]. One striking feature is a seismic gap in intermediate depth slab earthquakes observed beneath Cerro Galan $\left(25.5^{\circ} \mathrm{S}\right.$ and $\left.26.0^{\circ} \mathrm{S}\right)$.

[15] The relative shear wave velocity cross sections beneath Cerro Galan $\left(25.5^{\circ} \mathrm{S}\right.$ and $26.0^{\circ} \mathrm{S}$, Figures $7 \mathrm{a}$ and $7 \mathrm{~b}$ ) show the slab as a high velocity body, but surprisingly, they also contain a much faster block at around $140 \mathrm{~km}$ depth that seems to extend down to $190 \mathrm{~km}$ beneath northern Cerro Galan. At first, it may seem that this block could merely be part of the slab, but when comparing it to the slab contours, it appears that this high velocity body may be sitting on top of the slab. Figures $7 \mathrm{c}$ and $7 \mathrm{~d}$ show the slab as a high velocity body that correlates nicely with the slab contours from Mulcahy et al. [2010]. Figures 7a and 7b also show that to the east of the unusual high velocity body we see a low velocity zone that appears to spread well into the crust. It gets wider in the lower crust $(50 \mathrm{~km})$ and narrows as it reaches the surface beneath Cerro Galan and west Cerro 

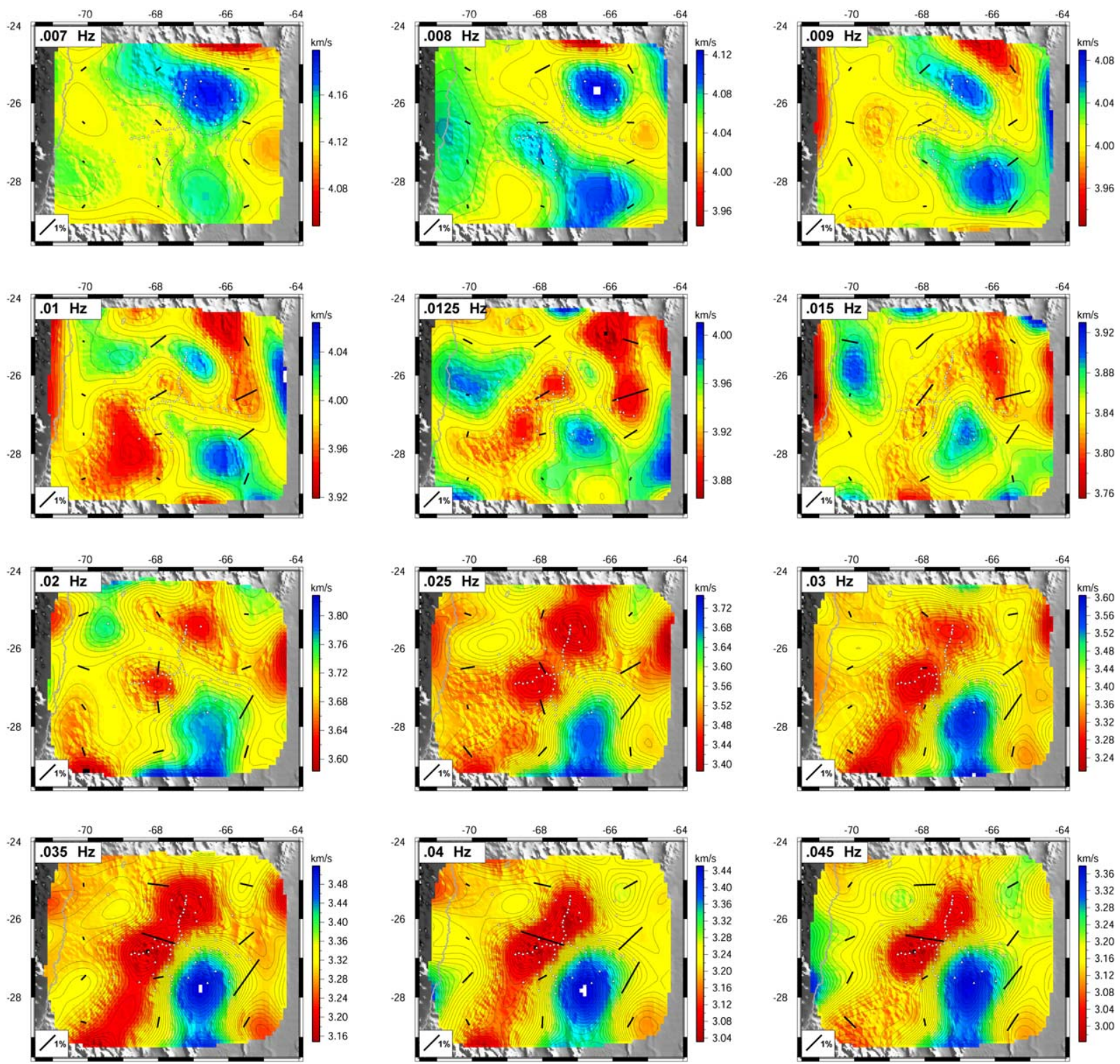

Figure 6. Map view of Rayleigh wave phase velocities for different frequency bands. Phase velocities values are plotted only for regions where the standard deviation does not exceed $0.1 \mathrm{~km} / \mathrm{s}$. High frequencies are sensitive to shallow structure as oppose to low frequencies, which are sensitive to deeper structures. The black lines are parallel to the fast direction and their size is proportional to the degree of anisotropy.

Galan. This low velocity zone extends to depths of about $50 \mathrm{~km}$ beneath Carachi Pampa and reaches the surface beneath Peinado (Figure 7c). The same low velocity is seen further south beneath Cerro Blanco and near the surface beneath the northern edge of Ojos del Salado (Figure 7d). The dispersion curves crossing the high velocity body at $\left(25.5^{\circ} \mathrm{S}, 66.9^{\circ} \mathrm{W}\right)$ and $\left(26.0^{\circ} \mathrm{S}, 66.6^{\circ} \mathrm{W}\right)$ suggest that Rayleigh wave velocities beneath northern Cerro Galan are slower than average for periods below $68 \mathrm{~s}$ (crustal depths), and faster than average for periods greater than $80 \mathrm{~s}$ (Figure 7e).
Faster shear wave velocities than average are also observed beneath northern Cerro Galan for depths greater than $140 \mathrm{~km}$, and slower shear wave velocities than average for depths shallower than 140 $\mathrm{km}$ (Figure 7f). The synthetic dispersion curves calculated from 1-D shear wave velocities beneath Cerro Galan at $\left(25.5^{\circ} \mathrm{S}, 66.9^{\circ} \mathrm{W}\right)$ and $\left(26.0^{\circ} \mathrm{S}\right.$, $66.6^{\circ} \mathrm{W}$ ) (vertical black lines in Figures $7 \mathrm{a}$ and $7 b$ ) show a very good fit with their corresponding measured phase velocities (Figure 7e).

[16] Figure 8 shows three-dimensional views of the shear-wave velocity anomalies greater than 1.0 

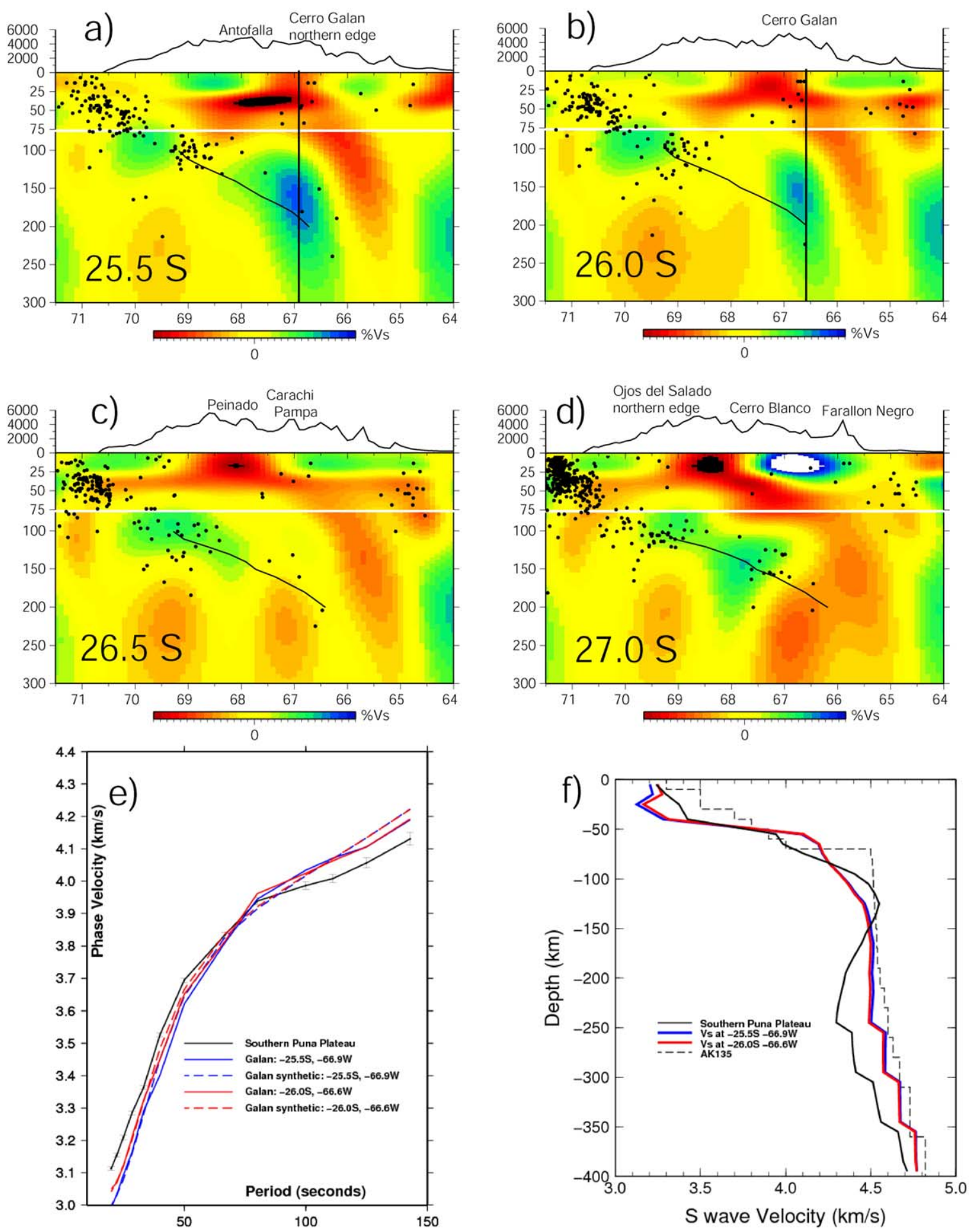

Figure 7. (a-d) East-west shear wave velocity anomaly cross sections at $25.5^{\circ} \mathrm{S}, 26.0^{\circ} \mathrm{S}, 26.5^{\circ} \mathrm{S}$, and $27.0^{\circ} \mathrm{S}$. The color scale minimum and maximum values correspond to $\pm 5 \%$ anomalies between 0 and $75 \mathrm{~km}$ depth, and $\pm 3 \%$ anomalies between 76 and $300 \mathrm{~km}$ depth. The black dots show the epicenters of regional earthquakes obtained from the PDE catalog. Slab contours from Mulcahy et al. [2010] are shown as thin black lines. Thick vertical black lines are the locations where the dispersion curves and inferred shear wave velocity model are shown in Figures 7e and 7f. (e) Dispersion curves beneath Cerro Galan at $\left(25.5^{\circ} \mathrm{S}, 69.9^{\circ} \mathrm{W}\right)$ and $\left(26.0^{\circ} \mathrm{S}, 66.6^{\circ} \mathrm{W}\right)$. Their respective synthetic dispersion curves and average dispersion curve for the southern Puna plateau are also shown for comparison. (f) Calculated shear wave velocity models beneath Cerro Galan at $\left(25.5^{\circ} \mathrm{S}, 69.9^{\circ} \mathrm{W}\right)$ and $\left(26.0^{\circ} \mathrm{S}, 66.6^{\circ} \mathrm{W}\right)$, average shear wave velocity model for the southern Puna plateau and initial shear wave velocity model (AK135). 

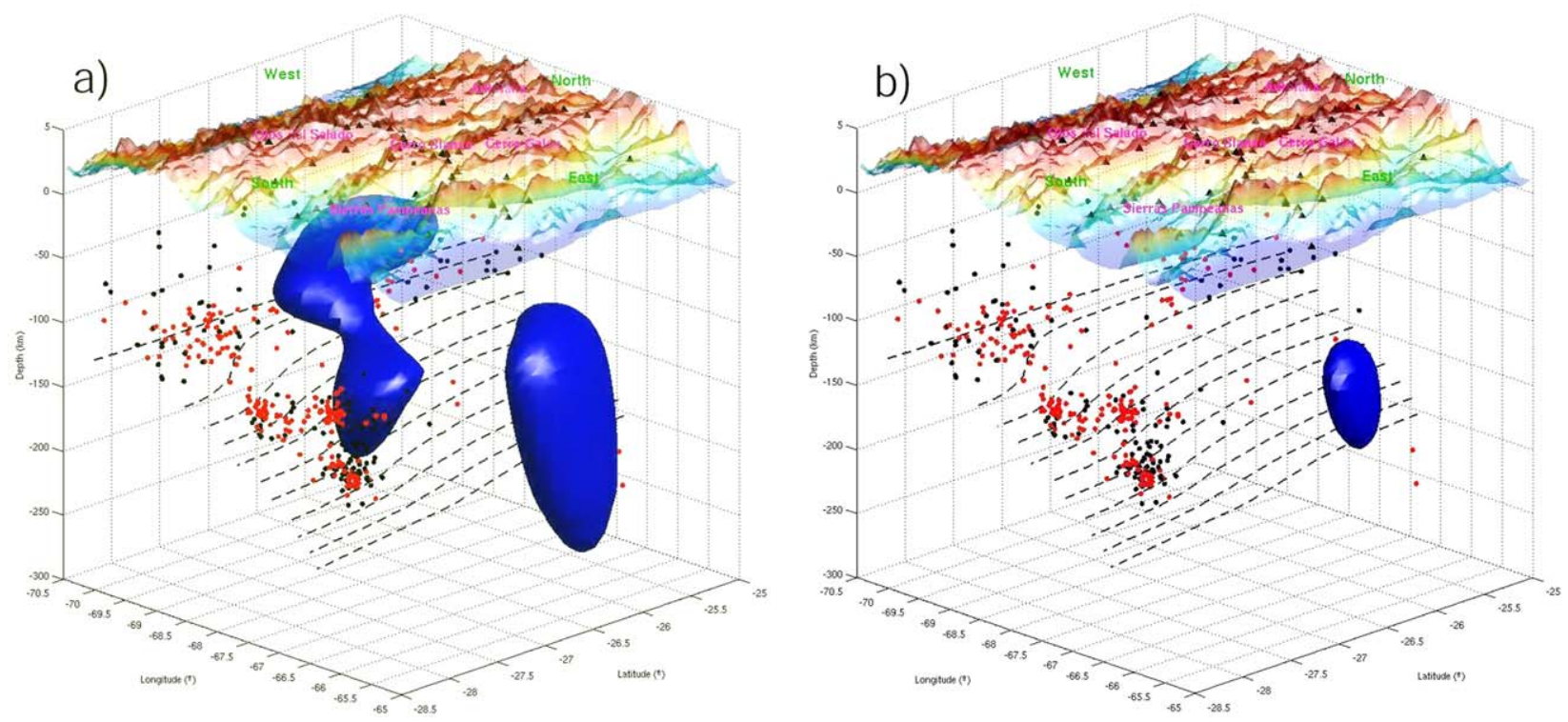

Figure 8. (a) Shear wave velocity anomalies of $1.0 \%$ and higher are shown in blue. The black dots are local earthquake locations obtained from the PDE catalog. The red dots earthquake locations and the slab contours shown in black dashed lines were obtained by Mulcahy et al. [2010]. The blue region is interpreted as the slab and the delaminated block combined. (b) Same as Figure 8a but showing shear wave velocity anomalies $2.0 \%$ and higher. The blue region only shows the delaminated block on top of the slab. Three-dimensional animations of these figures are available in the online version of this article.

and $2.0 \%$, respectively (three-dimensional animations of Figure 8 are available as supporting information). Figure 8 also shows the slab contours [Mulcahy et al., 2010] to illustrate where the slab is located with respect to these high velocity anomalies. When looking at high velocity anomalies greater than $1.0 \%$ (Figure $8 \mathrm{a}$ ), we clearly see the slab and the unusually high velocity body combined. We also observed a gap in the slab between Cerro Galan and Cerro Blanco, and it seems to spread toward the north-west. If, instead, the high velocity anomalies greater than $2.0 \%$ are plotted (Figure $8 \mathrm{~b}$ ), then the slab is not observed and only the abnormal high velocity block is seen in northern Cerro Galan, between $25.5^{\circ} \mathrm{S}$ and $26.0^{\circ} \mathrm{S}$. The unusual high velocity block is located above the slab contours, which suggest that it is not part of the slab.

\section{Discussion}

[17] Delamination is commonly referred to as the detachment and sinking of the lower portion of the continental lithosphere into the asthenosphere. Delamination is believed to be linked to shortening, which results in the formation of a denser crustal root. Delamination can also be linked to magmatic addition at the base of the crust. One of the effects of delamination is a thermal anomaly that leads to delamination magmatism, which is nonarc related and has a distinct chemical signature. Delamination also causes a regional change in stress orientation.

[18] In the southern Puna plateau, not only do we observe the effects listed above, but we also see surface manifestations of delamination magmatism. One of them is the Cerro Galan ignimbrite complex $(2.2 \mathrm{Ma})$, which is one of the largest in the Andes. Delamination in Cerro Galan was postulated by Kay and Kay [1993] to explain the rapid localized uplift and extension, and the increased magmatic production. This region exposes late Miocene and Pliocene volcanic rocks that are mostly silicic andesites and dacites, which are linked to crustal melting due to crustal thickening and plateau uplift. The southern Puna plateau also experienced a regional change in stress [Allmendinger et al., 1986, 1989; Marrett et al., 1994] from a very uniform NW-SE compressive regime in the Miocene to a more complex regime in the early Pliocene.

[19] Kay and Kay [1993] interpreted these observations as a detachment and sinking of a large portion of the continental lithosphere, which in turn caused asthenospheric uplift and changes in stress. The outbreak of the Cerro Galan ignimbrite complex was the result of mantle-derived magmas that ascended through strike-slip and normal faults that 
were created by the delamination event. The crustal chemical signature is due to the mixing of the mafic lavas with crustal melt on their way up to the surface. Recently, receiver function analysis using the same data set has shown that the crust beneath Cerro Galan is thicker than the rest of the southern Puna plateau. The crustal thickness in the southern Puna plateau $(40-70 \mathrm{~km})$ is thicker and weaker than that of eastern Turkey $(40-50 \mathrm{~km})$, and thinner and stronger than that of northern Tibet $(55-75 \mathrm{~km})$, which explains the fact that our average phase velocities for periods below $40 \mathrm{~s}$ (Figure 3a) are slower than those of eastern Turkey and faster than those of northern Tibet.

[20] The region of anomalous high velocity (greater than $2.0 \%$ ) at $140-190 \mathrm{~km}$ depth slightly to the north of Cerro Galan (Figures 7a, 7b, and 8b) is interpreted as delaminated crust. A comparison with the slab contours inferred from local seismicity [Mulcahy et al., 2010] suggests that this high velocity block is on top of the slab. Crustal phase velocities are slower than average and mantle phase velocities are higher than average beneath northern Cerro Galan (Figure 7e). The synthetic dispersion curves calculated from the 1-D shear wave velocities beneath Cerro Galan (Figure 7e) fit well with their respective dispersion curves. This demonstrates that our shear wave velocity model is robust and the data require the presence of a high velocity anomaly beneath northern Cerro Galan. Moreover, there is no apparent reason why part of a slab should have much higher seismic velocities than the rest of it. Other pieces of evidence that supports this idea were obtained from independent studies of attenuation tomography and teleseismic tomography that show a block of high Q on top of the slab (Liang et al., 2011) and a block of high $P$ wave velocity anomalies [Bianchi et al., 2013] imaged right where we see the high velocity block, but with a depth of around $100 \mathrm{~km}$. This difference in depth could be just a matter of resolution since surface wave tomography offers significantly better resolution than attenuation tomography or teleseismic tomography. However, the latter techniques provide better horizontal resolution than surface wave tomography.

[21] When looking at high velocity anomalies greater than $1.0 \%$ (Figures $8 \mathrm{a}$ ) we clearly see the slab and the delaminated block combined. The gap in the slab observed between Cerro Galan and Cerro Blanco correlates very well with the seismic gap and it might be just due to a thermal effect. We do not think that this is a real gap or tear in the slab but rather that the slab in this region is partially heated and could not be detected by the surface wave tomography method. The hypothesis of a thermally eroded slab could not be reconciled with the fact that there is no evidence for slab melting that reaches the surface. The idea of slab tear beneath Cerro Galan is very unlikely since the slab shows no tear further east down to around 500 $\mathrm{km}$. The low velocity region observed to the east of the delaminated block (Figures $7 \mathrm{a}$ and $7 \mathrm{~b}$ ) is interpreted as postdelamination asthenospheric upwelling that experiences decompression melting as it raises. Part of that hot asthenosphere caused widespread partial crustal melting as it reached the lower crust (Figures $7 \mathrm{a}$ and $7 \mathrm{~b}$, and Figure 6: 0.025-0.045 Hz). Eventually, the melted crust reached the surface and created the Cerro Galan ignimbrite complex. These low velocities (Figures $7 \mathrm{a}$ and $7 \mathrm{~b}$ ) correlate with the most recent nonarc related volcanism and ignimbrite complexes. Another part of the convecting asthenosphere reached the slab (gap observed in Figure 6: 0.007$0.009 \mathrm{~Hz}$ ) at about $120 \mathrm{~km}$ depth to the west of Cerro Galan (Figures 7a and 7b) and heated the slab, causing the gap observed in Figure 8a. This could also explain the low velocity zone observed in the dispersion curve for periods greater than $100 \mathrm{~s}$ (Figure 3a). We interpret the anomalous low velocities at depths below $200 \mathrm{~km}$ (Figure 3b) as caused by the well-documented recent change in angle of subduction, and the fact that the slab is partially heated by asthenospheric upwelling of hot asthenosphere that may have originated from depths as great as $250 \mathrm{~km}$. We would like to point out that low velocities at long periods are common for tectonically active regions like the Central Andean plateau or western United States (US). Pollitz and Snoke [2010] found Rayleigh wave phase velocities as low as $3.9 \mathrm{~km} / \mathrm{s}$ for $125 \mathrm{~s}$ for western US using local nonplane surface wave tomography. Wagner et al. [2010] measured 4.16 $\mathrm{km} / \mathrm{s}$ for $142 \mathrm{~s}$ for north-western US using Rayleigh wave tomography, close to our $4.13 \mathrm{~km} / \mathrm{s}$ for the same period. Moreover, a study of the upper mantle structure of South America using joint inversion of wave forms by Feng et al. [2007] found negative shear wave velocity variations of $-3.5 \%$ with respect to iasp91 $(4.506 \mathrm{~km} / \mathrm{s})$ at depths of $150 \mathrm{~km}$ for the southern Puna plateau. This corresponds to velocities of $4.348 \mathrm{~km} / \mathrm{s}$ (or $-4.01 \%$ deviation from AK135), which are even lower than our measured velocity of $4.47 \mathrm{~km} / \mathrm{s}$ at the same depth. The maximum negative deviation from $\mathrm{AK} 135$ from our current shear wave velocity 
model is $4.6 \%$ at depths around $250 \mathrm{~km}$, but this deviation decreases and the model approaches AK135 for greater depth (Figure 3b). This shows that, although unexpected, anomalous low phase velocities at long periods and shear wave velocities anomalies greater than $4 \%$ at depths below $150 \mathrm{~km}$ can actually be measured at tectonically active regions like the southern Puna plateau.

[22] We conjecture that delamination may have occurred in the region with the thinnest crust (region between Cerro Galan and Cerro Blanco), and that the delaminated block and asthenospheric flow may have migrated northward. A trench parallel asthenospheric flow could explain why the delaminated block and Cerro Galan are north of the region with the thinnest crust. This is seen in the predominantly north-south pattern of fast direction from shear wave splitting analysis [Calixto et al., 2012]. The slab geometry, flat in the south and steep in the north could also facilitate a northward flow of asthenosphere, which could be related to the idea of northward motion of the delaminated block. The primarily east-west NUVEL-1 convergence rate of $8.5 \mathrm{~cm} / \mathrm{yr}$ of the Nazca plate respect to the South American plate would not be enough to explain such a motion.

[23] Delamination seems to be a very likely candidate that explains many of the geochemistry and geophysical observations throughout the southern Puna plateau. Although our images are not conclusive, there seems to be a delaminated block sinking and migrating northward beneath Cerro Galan. Such a block is causing asthenospheric upwelling and a number of other perturbations in the region, including regional changes in stress regime, rapid uplift, and eruption of young ignimbrites. Heating of the slab by the upwelling of hot asthenosphere could be responsible for the gap in intermediate seismicity right beneath Cerro Galan, which precludes us from better constraining the subducting slab. The lower crust beneath Galan is also very hot as evidenced by the low velocities shown at high frequencies in Figure 6. This agrees with the impulsive $P$ wave and almost no energy in the $S$ waves observed in the few earthquakes detected in the gap [Mulcahy et al., 2010].

[24] The size of the delaminated block estimated by Kay and Kay [1993], using purely chemical methods, is in strong agreement with the size of the high velocity block imaged at $140-190 \mathrm{~km}$ depth slightly to the north of Cerro Galan (Figure 8b). Schurr et al. [2003, 2006] found a similar formation in the back arc of the Puna at $23.1^{\circ} \mathrm{S}$. They see a region of high velocity and low attenuation interpreted as a $50 \mathrm{~km}$ thick delaminated lithosphere. Very similar thickness to the delaminated block imaged in this paper. We conjecture that this thickness has a direct link with the initialization of the instability leading to delamination.

[25] Shear wave splitting [Calixto et al., 2012] gives further evidence for the current complex regional stress and strain patterns throughout the crust and upper mantle. A circular pattern of fast directions around Cerro Galan seems to be linked to asthenospheric upwelling around the delaminated block.

\section{Conclusions}

[26] The evidence for delamination of the lithosphere 7-6 Ma beneath the largest ignimbrite in the southern Puna plateau, Cerro Galan, is very strong, though not conclusive. The change of surface wave phase velocities and shear wave velocities from anomalously low values at shallow depths to anomalously high values at greater depths may be the result of a downwelling or detachment of cold lithosphere followed by upwelling of hotter upper mantle filling the gap left by the downwelling lithosphere. A region of abnormally high shear wave velocities on top of the slab beneath the northern edge of Galan is interpreted as the delaminated block. This block is also seen in independent studies as a block of high $Q$ (Liang et al., 2011) and high $P$ wave velocity anomalies [Bianchi et al., 2013].

[27] The delamination hypothesis is consistent with the model of Kay and Coira [2009] in which a moderately shallowly dipping slab causes a significant amount of back arc volcanism and delamination of dense lithosphere as the slab steepened, followed by the eruption of the Cerro Galan ignimbrite with the most recent event occurring around $2 \mathrm{Ma}$. All this evidence indicates that the lower lithosphere, including the eclogitic root beneath the region between Cerro Galan and Cerro Blanco, detached and sank migrating northward, and led to postdelamination asthenosphere upwelling, which probably underwent partial melting during its ascent. The insertion of hot asthenosphere from depths as great as $250 \mathrm{~km}$ into the mantle wedge caused widespread lower crust melting and an increase in temperature of the top of the slab at $120 \mathrm{~km}$ beneath the west of Cerro Galan, making it less brittle and reducing the 
friction with the mantle wedge. Over time, the top of the slab and the injection of hot asthenosphere may have reached thermal equilibrium, and it is the reason why we do not observe a geophysical difference between the slab and the mantle wedge in the seismic gap. The heated slab explains the scarce local seismicity in this part of the southern Puna plateau as compared to surrounding regions. It is also important to remark that all the evidence including the low velocities in the lower crust suggests that the ignimbrite flare up is not over.

[28] Further investigation needs to be done in order to further resolve the high velocity block observed beneath Cerro Galan. This includes performing a joint inversion of surface waves and body waves.

\section{Acknowledgments}

[29] We are grateful to Dayanthie Weeraratne for reviewing and providing outstanding comments that helped improve our long period measurements and the manuscript. We also thank Thorsten Becker (Editor of G-cubed), an anonymous associate editor and an anonymous reviewer for their helpful comments and suggestions that led to great improvements in the content and presentation of this article. We also thank IRIS and GEOFON for the archiving of continuous waveform. This work was funded by the NSF grant proposal EAR-0538245.

\section{References}

Allmendinger, R. W. (1986), Tectonic development of the southeastern border of the Puna Plateau, northwestern Argentine Andes, Geol. Soc. Am. Bull., 97, 1070-1082.

Allmendinger, R. W., M. A. Strecker, J. E. Eremchuk, and P. W. Francis (1989), Neotectonic deformation of the southern Puna Plateau, northwestern Argentina, J. South Am. Earth Sci., 2, 111-130.

Babeyko, A. Y., S. V. Sobolev, R. B. Trumbull, O. Oncken, and L. L. Lavier (2002), Numerical models of crustal scale convection and partial melting beneath the Altiplano-Puna Plateau, Earth Planet. Sci. Lett., 199, 373-388, doi:10.1016/ S0012-821X(02)00597-6.

Beck, S., and G. Zandt (2002), The nature of orogenic crust in the central Andes, J. Geophys. Res., 107(B10), 2230, doi:10.1029/2000JB000124.

Bianchi, M., B. Heit, A. Jakovlev, X. Yuan, S. M. Kay, E. Sandvol, R. N. Alonso, B. Coira, L. Brown, R. Kind, and D. Comte (2013), Teleseismic tomography of the southern Puna plateau in Argentina and adjacent regions, Tectonophysics, 586, 65-83.

Bird, P. (1979), Continental delamination and the Colorado Plateau, J. Geophys. Res., 84, 7561-7571.

Cahill, T. A., and B. L. Isacks (1992), Seismicity and shape of the subducted Nazca plate, J. Geophys. Res., 97, 17,50317,529, doi:10.1029/92JB00493.

Calixto, F. J., D. L. Abt, K. M. Fischer, B. Heit, X. Yuan, S. M. Kay, D. Comte, P. Alvarado, and E. Sandvol (2012),
Three dimensional anisotropic structure of the southern Puna plateau, Abstract S44A-07 presented at 2012 Fall Meeting, AGU, San Francisco, Calif.

Ceylan, S., J. Ni, J. Y. Chen, Q. Zhang, F. Tilmann, and E. Sandvol (2012), Fragmented Indian plate and vertically coherent deformation beneath eastern Tibet, J. Geophys. Res., 117, B11303, doi:10.1029/2012JB009210.

Ducea, M., S. Kidder, and G. Zandt (2003), Arc composition at mid-crustal depths: Insights from the Coast Ridge Belt, Santa Lucia Mountains, California, Geophys. Res. Lett., 30(13), 1703, doi:10.1029/2002GL016297.

England, P. C., and G. A. Houseman (1988), The mechanics of the Tibetan Plateau. Tectonic evolution of the Himalayas and Tibet, Philos. Trans. R. Soc. London A, 326(1589), 301-320.

Feng, M., S. van der Lee, and M. Assumpcao (2007), Upper mantle structure of South America from joint inversion of waveforms and fundamental mode group velocities of Rayleigh waves, J. Geophys. Res., 112, B04312, doi:10.1029/ 2006JB004449.

Forsyth, D. W., and A. Li (2005), Array-analysis of twodimensional variations in surface wave velocity and Azimuthal anisotropy in the presence of multipathing interference, in Seismic Earth: Array Analysis of Broadband Seismograms, Geophys. Monogr. Ser., edited by A. Levander and G. Nolet, pp. 81-97, 157, AGU, Washington, D. C.

Herquel, G., G. Wittlinger, and J. Guilbert (1995), Anisotropy and crustal thickness of Northern-Tibet. New constraints for tectonic modelling, Geophys. Res. Lett., 22, 1925-1928.

Holt, W., and T. Wallace (1990), Crustal thickness and upper mantle velocities in the Tibetan Plateau region from the inversion of regional $P n l$ waveforms: Evidence for a thick upper mantle lid beneath southern Tibet, J. Geophys. Res., 95, 12,499-12,525.

Isacks, B. L. (1988), Uplift of the central Andean plateau and bending of the Bolivian orocline, J. Geophys. Res., 93, 3211-3231.

Jull, M., and P. B. Keleman (2002), On the conditions for lower crustal convective instability, J. Geophys. Res., 106(B4), 6423-6446, doi:10.1029/2000JB900357.

Karsli, O., A. Dokuz, I. Uysal, F. Aydin, R. Kandemir, and J. Wijbrans (2010), Generation of the early Cenozoic adakitic volcanism by partial melting of mafic lower crust, Eastern Turkey: Implications for crustal thickening to delamination, Lithos, 114, 109-120, doi:10.1016/j.lithos.2009.08.003.

Kay, R. W., and S. M. Kay (1993), Delamination and delamination magmatism, Tectonophysics, 219, 177-189.

Kay, S. M., B. Coira, and J. Viramonte (1994), Young mafic back arc volcanic rocks as indicators of continental lithospheric delamination beneath the Argentine Puna plateau, central Andes, J. Geophys. Res., 99, 24,323-24,339.

Kay, S. M., E. Godoy, and A. Kurtz (2005), Episodic arc migration, crustal thickening, subduction erosion, and Miocene to recent magmatism along the Andean southern volcanic zone margin, Geol. Soc. Am. Bull., 117, 67-88.

Kay, S. M. and B. Coira (2009), Shallowing and steeping subduction zones, continental lithospheric loss, magmatism, and crustal flow under the Central Andean Altiplano-Puna Plateau, Geol. Soc. Am. Bull., 204, 229-259.

Li, A. (2011), Shear wave model of southern Africa from regional Rayleigh wave tomography with 2-D sensitivity kernels, Geophys. J. Int., 185, 832-844.

Liang, X., E. Sandvol, L. Brown, B. Heit, X. Yuan, P. Mulcahy, C. Chen, and S. Kay (2011), The Q images of southern Puna plateu from bodywave attenuation tomography, 
Abstract S51C-2226 presented at 2011 Fall Meeting, AGU, San Francisco, Calif.

Marrett, R. A., R. W. Allmendiger, R. N. Alonso, and R. E. Drake (1994), Late Ceonozoic tectonic evolution of the Puna Plateau and adjacent foreland northwestern Argentine Andes, J. South Am. Earth Sci., 7, 179-207.

Mulcahy, P., C. Chen, S. M. Kay, L. D. Brown, P. Alvarado, E. Sandvol, B. Heit, and X. Yuan (2010), The southern Puna seismic experiment: Shape of the subducting Nazca plate, areas of concentrated mantle and crustal earthquakes, and crustal focal mechanisms, Abstract T11A-2050 presented at 2010 Fall Meeting, AGU, San Francisco, Calif.

Pollitz, F., and J. Snoke (2010), Rayleigh-wave phase-velocity maps and three-dimensional shear velocity structure of the western US from local non-plane surface wave tomography, Geophys. J. Int., 180, 1153-1169.

Rudnick, R. L. (1995), Making continental crust, Nature, 378, 571-578.

Saito, M. (1988), DISPER80: A subroutine package for calculation of seismic normal-mode solution, in Seismological Algorithms, edited by D. J. Doornbos, pp. 293-319, Elsevier, New York, N. Y.

Schurr, B., G. Asch, A. Rietbrock, R. Trumbull, and C. Haberland (2003), Complex patterns of fluid and melt transport in the Central Andean subduction zone revealed by attenuation tomography, Earth Planet. Sci. Lett., 215, 105-119, doi:10.1016/S0012-821X(03)00441-2.

Schurr, B., A. Rietbrock, G. Asch, R. Kind, and O. Oncken (2006), Evidence for lithospheric detachment in the central Andes from local earthquake tomography, Tectonophysics, 415, 203-223, doi:10.1016/j.tecto.2005.12.007.
Smith, M. L., and F. A. Dahlen (1973), The azimuthal dependence of Love and Rayleigh wave propagation in a slightly anisotropic medium, J. Geophys. Res., 78, 3321-3333.

Sobolev, S. V., and A. Y. Babeyko (2005), What drives orogeny in the Andes?, Geology, 33, 617-620, doi:10.1130/ G21557.1.

Von Huene, R., and D. W. Scholl (1991), Observations at convergent margins concerning sediment subduction, subduction erosion, and the growth of continental crust, Rev. Geophys., 29, 279-316.

Wagner, L., D. Forsyth, M. Fouch, and D. James (2010), Detailed three-dimensional shear wave velocity structure of the northwestern United States from Rayleigh wave tomography, Earth Planet. Sci. Lett., 299, 273-284.

Wang, Q., S. Chung, X. Li, D. Wyman, Z. Li, W. Sun, H. Qiu, Y. Liu, and Y. Zhu (2012), Crustal melting and flow beneath northern Tibet: Evidence from Mid-Miocene to quaternary strongly peraluminous Rhyolites in the southern Kunlun range, J. Petrol., 53, 2523-2566.

Yang, Y., and D. W. Forsyth (2006a), Rayleigh wave phase velocities, small-scale convection, and azimuthal anisotropy beneath southern California, J. Geophys. Res., 111, B07306, doi:10.1029/2005JB004180.

Yang, Y., and D. W. Forsyth (2006b), Regional tomographic inversion of amplitude and phase of Rayleigh waves with 2-D sensitivity kernels, Geophys. J. Int., 166, $1148-1160$.

Zor, E., E. Sandvol, C. Gürbüz, N. Türkelli, D. Seber, and M. Barazangi (2003), The crustal structure of the east Anatolian plateau (Turkey) from receiver functions, Geophys. Res. Lett., 30(24), 8044, doi:10.1029/2003GL018192. 